\section{Is an iris claw IOL a good option for correcting surgically induced aphakia in children? A review of the literature and illustrative case study}

\begin{abstract}
Refractive correction of aphakia in childhood can be a complex management issue following lensectomy for congenital cataract or ectopia lentis. Some children have inadequate capsular support to allow an 'in the bag' or sulcus fixated intra-ocular lens (IOL). In such cases, options for refractive correction include spectacles, contact lenses, or surgically fixed IOLs. Many methods of IOL fixation have been described, but none are widely adopted in children. In recent years, the iris-fixated Artisan Aphakic IOL has gained popularity, but there is still significant concern about the rate of corneal endothelial cell loss and IOL de-enclavation. Here, we review the current literature on the use of iris-fixated IOLs in children, the published data on endothelial cell loss and de-enclavation rates. We present a case illustrating the significant improvements in quality of life, which can be seen in selected children, and also the rate of endothelial cell loss, which can be encountered after initial surgery, and a re-enclavation event. We make the case that until more data are available on normal endothelial cell decline in early childhood, in addition to age-specific rates of endothelial cell loss and de-enclavation rates following surgery, the use of iris-fixated IOLs in children will continue to be a moot point and is unlikely to be widely adopted. Eye (2016) 30, 1155-1159; doi:10.1038/eye.2016.140; published online 8 July 2016
\end{abstract}

\section{Introduction}

Ectopia lentis is subluxation of the natural crystalline lens. It can be congenital, developmental, or acquired. Hereditary disorders such as homocystinuria, Sulfite oxidase deficiency, hyperlysinemia, Marfan

R Barbara ${ }^{1}$, SR Rufai ${ }^{1,2}$, N Tan ${ }^{2}$ and JE Self ${ }^{1,2}$

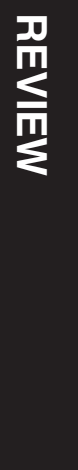

syndrome, Weill-Marchesani syndrome, and Ehler-Danlos syndrome are known associations. ${ }^{1}$ Complications of ectopia lentis include: significant and progressive refractive error, amblyopia, and glaucoma. Dislocation of the lens into the anterior or posterior chamber can result in angle closure, pupillary block, damage to the corneal endothelium, and retinal detachment. ${ }^{2}$ Surgery to remove a subluxed lens most commonly includes removal of the crystalline lens, in addition to the lens capsule, and an anterior vitrectomy leaving the eye aphakic. Options for the correction of the consequent aphakia in children includes conservative refractive correction using contact lenses or spectacles, iris-supported intra-ocular lenses (IOLs), and trans-scleral fixation of posterior chamber IOL. ${ }^{3,4}$ Scleral fixation of posterior chamber IOLs in children have not gained significant support owing to cases of lens tilt, dislocation, infection, and erosion of scleral sutures. ${ }^{5}$ Newer techniques of scleral fixation using a scleral tunnel have been developed to avoid suture-related complications, but again, are not widely reported in children. ${ }^{6}$

Iris-fixated anterior chamber IOLs such as the Artisan Aphakic IOL (Ophtec BV, Groningen, The Netherlands) has gained support in recent years as a suitable alternative. It has been successfully implanted in children with congenital cataract, myopic anisometropic amblyopia, and subluxated lenses. ${ }^{1,7,8}$ However, concerns regarding chronic endothelial cell loss (ECL) and the risk of lens de-enclavation from the iris have continued, in part, owing to lack of data in the literature for these cases.

In addition, a variety of surgical modifications (such as anterior $v s$ posterior iris fixation)
${ }^{1}$ Southampton Eye Unit, University Hospital Southampton, Southampton, UK

${ }^{2}$ Faculty of Medicine, University of Southampton, Southampton, UK

Correspondence: R Barbara, Southampton Eye Unit, Southampton General Hospital, Southampton SO16 6YD UK Tel: +44 238120 3617; Fax: +44 2381204120 E-mail: Ramezborbara@ gmail.com

Received: 30 April 2016 Accepted in revised form: 13 June 2016 Published online: 8 July 2016 
have been considered, but again, are largely unsupported by significant data in the literature.

\section{Case study}

A 5-year-old child was referred to our ophthalmology tertiary referral centre owing to bilateral lens subluxation. He described recent difficulties with reading and in navigating his surroundings resulting in frequent minor injuries. He had a pre-existing clinical diagnosis of Marfan syndrome with secondary aortic root dilatation, and was under the care of the paediatric cardiology team. His only medication was Atenolol $25 \mathrm{mg}$ daily. There was no other relevant family history.

On examination, his uncorrected distant visual acuity was $6 / 60 \mathrm{OD}$ and $6 / 48 \mathrm{OS}$. Cycloplegic refraction was $-8.50 \mathrm{D}-1.00 \mathrm{D} \times 90$ achieving best spectacle corrected visual acuity (BSCVA) of $6 / 12$ and $-7.00 \mathrm{D}-1.00 \mathrm{D} \times 90$ achieving $6 / 12$, respectively. His uncorrected near visual acuity was $6 / 15$ OD and $6 / 20$ OS improving to $6 / 9$ and $6 / 6$ with +2.00 add, respectively. Anterior segment examination revealed bilateral subluxed lenses, to a greater degree in the left eye; superio-nasal in the right, and superio-temporal in the left eye. The rest of the anterior and posterior segment examinations were unremarkable.

He was followed-up over the next 3 years and the luxation remained stable, however, his degree of myopia increased. Refraction was $-9.00-1.75 \times 95$ OD and $-9.50-1.25 \times 140$ achieving BSCVA of $6 / 9$ OU. At that stage it was agreed to proceed with lens extraction and he had right followed by left lensectomy and anterior vitrectomy a week apart, without lens implantation. Surgery was performed through two 23G limbal incisions superiorly and inferiorly, HEALON (Abbott Laboratories Inc., Abbott Park, IL, USA), a small capsulorhexis using cystotome and intra-ocular forceps, lens aspiration, and removal of the capsular bag and anterior vitrectomy. The pupil was then miosed and a peripheral irridotomy performed. Corneolimbal wounds were sutured using 10.0 Vicryl (Ethicon, Somerville, NJ, USA).

Refraction was +15.50D $-1.00 \mathrm{D} \times 180 \mathrm{OD}$ and $+14.00 \mathrm{D}$ $-1.25 \mathrm{D} \times 100 \mathrm{OS}$. He was fitted with hard contact lenses in the right and left eye; +18.00 achieving $6 / 7$ vision and +16.00 achieving $6 / 7$, respectively.

At this stage he was fitted with contact lenses to maximise his visual potential, nevertheless, he was intolerant to his contact lenses and refused to wear glasses. This affected his quality of life, and his adaptation and performance at school suffered significantly. After discussion with the patient and family, a decision was taken to perform secondary IOL implantation. Six months post lensectomy, an Artisan aphakic IOL (Ophtec BV; $5.4 \mathrm{~mm}$ optic - model 205) was implanted with iridotomy in each eye, separated by 2 weeks. The IOL power was calculated using the manufacturer's formula. Post-operative refraction was $+1.50 \mathrm{D}-2.00 \mathrm{D} \times 50$ achieving BSCVA of $6 / 6-\mathrm{OD}$ and $+1.25 \mathrm{D}-1.50 \mathrm{D} \times 145$ achieving BSCVA of $6 / 6-\mathrm{OS}$. By adding +2.75 he was able to read to N5. Intra-ocular pressure was within the normal range at all points in the pre- and post-operative periods.

\section{Surgical technique for Artisan aphakic IOL implantation}

The operation was performed under general anaesthetic. Standard prepping and draping as applied. A 6-mm scleral incision, $2 \mathrm{~mm}$ from limbus, and two 23G paracenteses were performed. Intracameral Miochol was applied to constrict the pupil. A straight incision using 5.50- $\mu$ g blade and crescent knife was performed through the scleral incision. A 19.5D Artisan aphakia 5/8.5 lens implanted in the right eye and $+20 \mathrm{D}$ in the left eye and rotated with a lens dialer. Enclavation performed using enclavation hook. This was repeated for both haptics. The scleral wounds were sutured using 10.0 vicryl (Ethicon). Intracameral heparin and cefuroxime were followed by subconjunctival cefuroxime and dexamethasone. (see figure 1a).

Subsequently, the child's problems at school reversed, and he was able to function well with no correction for the
OD

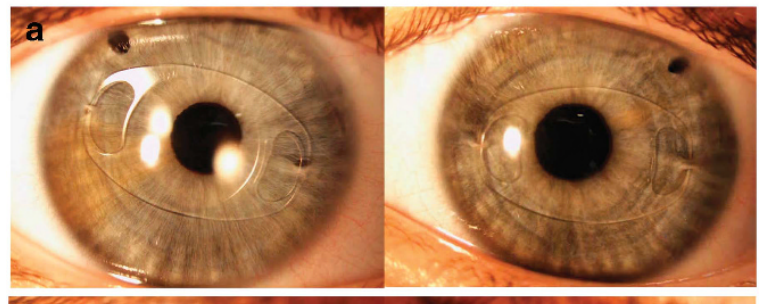

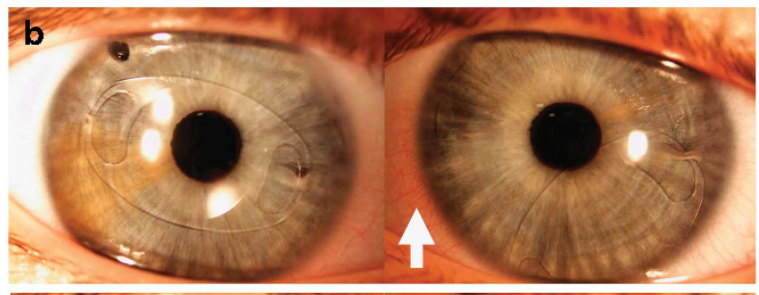

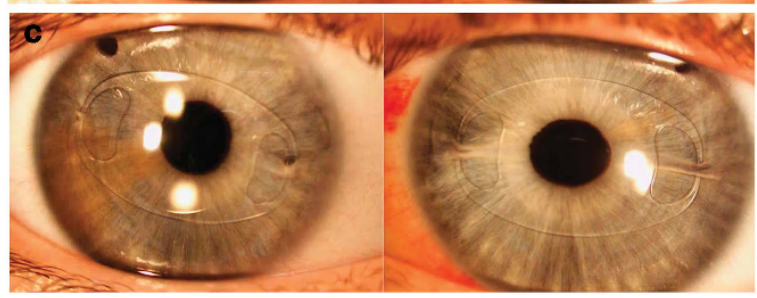

Figure 1 Anterior slit-lamp images. (a) Showing bilateral artisan phakic IOL; (b) OD demonstrating enclavated artisan aphakic IOL, OS demonstrating de-enclavation of the nasal haptic and dislodging of the artisan IOL inferiorly. Arrow indicates nasal conjunctival injection corresponding to the area of trauma. (c) Reenclavation of the nasal haptic artisan OS IOL. 
majority of activities and his family reported a profound improvement to his quality of life.

Six months following Artisan IOL implantation in the left eye, the patient incurred traumatic injury which resulted in unclipping of the nasal haptic (see Figure 1b). There was mild conjunctival injection nasal to the unclipped haptic (Figure 1b arrow), there were no signs of haemorrhage or uveitis. Repositioning of the Artisan phakic IOL was performed in theatre 2 days following the injury. During re-enclavation of the nasal haptic it was also necessary to reposition the temporal haptic. Subsequently, the patient's visual function returned swiftly and his refraction was $+1.25,-1.50 \times 145$ achieving BSCVA of $6 / 6$.

\section{Endothelial cell count}

Endothelial cell count (ECC) was performed initially using the Topcon SP-3000P Non-Contact Specular Microscope (Topcon Corporation, Tokyo, Japan) and subsequently using the Nidek CEM-530 (NIDEK Co. Ltd., Gamagori, Aichi, Japan).

ECC measurements were performed before and after lensectomy, and following Artisan IOL implantation and repositioning of the left Artisan IOL. We present 12-month follow-up post artisan implantation.

Specular microscopy analysis is displayed in Table 1. $\mathrm{SD}$ and CV measurements are not consistent between the two machines used as the cells were manually selected in the Topocon specular microscope (Capelle aan den IJssel, The Netherlands).

\section{Discussion}

Ectopia lentis occurs in at least $50 \%$ of patient with Marfan syndrome. ${ }^{9}$ Lensectomy in children with Marfan syndrome invariably includes removal of the capsular bag and support structures in addition to an anterior vitrectomy. In some older patients capsular tension rings may be used when limited zonular dehiscence is present. ${ }^{10}$ However, these techniques are rarely used owing to highly reported complication rate.

The Artisan IOL was invented by Worst et al ${ }^{11}$ in 1986 and was initially known as the Worst-Fechner claw lens. Its main use was for the phakic high myopia correction. The aphakic model is $5.4 \mathrm{~mm}$ biconvex (AC 205 model, Ophtec BV) made of PMMA. It is designed to anchor at the iris mid-periphery which is considered immobile and is not in contact with the iris except at the fixation point, and therefore avoids pigment dispersion. Moreover, it has a vaulted design that provides optimal space between the iris and the Artisan IOL, thereby avoiding interference with aqueous flow. ${ }^{1,12}$

Few reports describe the use of Artisan aphakic IOL in the paediatric age group. Worst described its use for congenital, traumatic, and developmental cataracts. ${ }^{13}$ Lifshitz et al ${ }^{1}$ and Gawdat et al ${ }^{12}$ have described Artisan aphakic implantation in paediatric aphakia with insufficient capsular support. Sminia describes the use of Artisan iris reconstruction using an IOL for aphakia and partial aniridia secondary to perforating ocular trauma. ${ }^{14}$

Children have long mean life expectancy, therefore long-term monitoring of ECL is important following Artisan IOL implantation. It is reported that the ECC at birth is 6000 cells $/ \mathrm{mm}^{2}$ which decreases at a rate of $13 \%$ between $5-7$ years and a further $12 \%$ by the age of 10 years. ${ }^{15,16}$ ECL is estimated to be $6 \%$ post paediatric cataract lensectomy, ${ }^{17,18}$ but is very likely technique, age and indication specific.

Table 1 A full corneal endothelial cell morphology analysis of patient during pre-implantation of Artisan lens, post-implantation of artisan lens, and post Artisan re-enclavation

\begin{tabular}{|c|c|c|c|c|c|c|c|c|c|c|c|}
\hline & \multicolumn{5}{|c|}{$O D$} & & \multicolumn{5}{|c|}{ OS } \\
\hline & NUM & $\begin{array}{l}A V G \\
\left(\mu m^{2}\right)\end{array}$ & $\begin{array}{l}C V \\
(\%)\end{array}$ & $\begin{array}{c}H E X \\
(\%)\end{array}$ & $\begin{array}{c}E C D \\
\left(\text { cells } / m^{2} m^{2}\right)\end{array}$ & & NUM & $\begin{array}{l}A V G \\
\left(\mu m^{2}\right)\end{array}$ & $\begin{array}{l}C V \\
(\%)\end{array}$ & $\begin{array}{c}H E X \\
(\%)\end{array}$ & $\begin{array}{c}E C D \\
\left(\text { cells } / m^{2} m^{2}\right)\end{array}$ \\
\hline Pre-Artisan ${ }^{\mathrm{a}}$ & $\mathrm{N} / \mathrm{A}$ & $\mathrm{N} / \mathrm{A}$ & N/A & N/A & 3326 & Pre-Artisan ${ }^{\mathrm{a}}$ & $\mathrm{N} / \mathrm{A}$ & $\mathrm{N} / \mathrm{A}$ & $\mathrm{N} / \mathrm{A}$ & N/A & 3274 \\
\hline 1 week post Artisan ${ }^{\mathrm{a}}$ & 10 & 318 & 14 & $\mathrm{~N} / \mathrm{A}$ & 3137 & 1 week post Artisan ${ }^{a}$ & 10 & 341 & 11 & N/A & 2930 \\
\hline 1 month post Artisan ${ }^{a}$ & 10 & 313 & 9 & $\mathrm{~N} / \mathrm{A}$ & 3192 & 1 month post Artisan ${ }^{a}$ & 10 & 342 & 11 & $\mathrm{~N} / \mathrm{A}$ & 2920 \\
\hline 8 months post Artisan ${ }^{\mathrm{b}}$ & 209 & 329 & 22 & 72 & 3038 & $\begin{array}{l}1 \text { week post Artisan } \\
\text { re-enclavation ( } 8 \text { months } \\
\text { post Artisan) })^{\mathrm{b}}\end{array}$ & 162 & 368 & 23 & 74 & 2721 \\
\hline 10 months post Artisan ${ }^{\mathrm{b}}$ & 218 & 344 & 24 & 70 & 2908 & $\begin{array}{l}2 \text { months post Artisan } \\
\text { re-enclavation }(10 \text { months } \\
\text { post Artisan) }\end{array}$ & 148 & 403 & 25 & 70 & 2483 \\
\hline 12 months post Artisan ${ }^{\mathrm{b}}$ & 203 & 328 & 26 & 72 & 3053 & $\begin{array}{l}4 \text { months post Artisan } \\
\text { re-enclavation ( } 12 \text { months } \\
\text { post Artisan) }\end{array}$ & 166 & 415 & 26 & 73 & 2411 \\
\hline
\end{tabular}

Abbreviations: AVG, average cell surface area; CV, coefficient of variation; ECD, endothelial cell density; HEX, hexagonality; NA, not applicable; NUM, number of cells detected. ${ }^{\mathrm{a}}$ Topcon SP-2000P Specular Microscope used. ${ }^{\mathrm{b}}$ Nidek CEM-530 Specular Microscope used. 
Our case report demonstrates that Artisan IOL implantation resulted in ECL and subsequent reduction in ECC was noted at each follow-up visit in the postoperative period. This drop in ECC was regardless of the de-enclavation and the different machines used. Clearly, this corresponds to reduction in cell hexagonality and increase in coefficient of variation and standard deviation, especially when comparing measurement performed using the same specular microscope (NIDEK Co. Ltd.). At 1 year post artisan implantation, ECL started to stabilise for the left eye and might have been halted for the right eye.

This is similar to other published findings which demonstrate that ECL is higher in the first year post aphakic Artisan IOL implantation, with a further drop noted over the subsequent years to a lesser extent-this seems to stabilise 3 years post operatively. ${ }^{12,19,20}$ In a multicentre study of Artisan phakic IOL, ECL was found to stabilise 3 years post operatively. ${ }^{19}$ It seems that there are two stages for ECL; the intra-operative stage, where most ECL occurs, and 2-3 years post operatively.

Generally, there are concerns regarding cornea-IOL contact, especially during eye rubbing. In a large case series it was reported that $1.7 \%$ of patients had corneal decompensation at 2 years post IOL implantation in adults following penetrating injury. ${ }^{21}$

The longest follow-up is of two children with Marfan syndrome and bilateral lens dislocation, both who had lensectomy with aphakic Artisan IOL implantation. At 12 years, ECC was similar to eyes without crystalline lens surgery, but the coefficient of variation of cell size was higher and hexagonality of cells was lower. These morphological changes are reported in non-operated eyes of Marfan patients, especially with lens dislocation. ${ }^{22}$

Our case report demonstrates a further drop in ECC following de-enclavation of the Artisan in the left eye. We believe that this is most likely related directly to the traumatic event in addition to the IOL re-enclavation procedure, rather than the period of IOL malpositioned per se as the anterior chamber was very deep in this eye and one haptic was still attached preventing complete free movement of the IOL.

Complications of artisan IOL implantation may require surgical intervention, as demonstrated in our case report. Sminia et al ${ }^{14}$ reports $40 \%$ (2/5) iris claw luxation. Gawdat et $a l^{12}$ reported no spontaneous de-enclavation of IOL. De Silva et $a l^{21}$ reports iris claw de-enclavaion to be at $6 \%$ in adult patients. Early dislocations were attributed to the insertion technique and that later on in their series, these dislocations were reduced attributing that to a learning curve.

It is also possible that enclavation of a larger amount of iris tissue may have prevented de-enclavation in our paediatric case. It seems that the amount of enclavated tissue may be an important consideration when investigating de-enclavation rates, particularly in children. Traumatic Artisan aphakic IOL dislocations are seldom reported in the literature.

This case reports demonstrates the accelerated ECL in the first year post cataract and Artisan IOL implantation, which is consistent with other reported results. Artisan Aphakic IOLs are gaining popularity as a means of visual rehabilitation in paediatric patients with insufficient capsular support. Chronic ECL appears to occur as a result of the surgery itself and not owing to the presence of IOL per se, neverthelress, further study is needed.

A weakness in the present case is the use of two different instruments to measure ECC. Although SD and $\mathrm{CV}$ were significantly different and not comparable, ECC was valid.

It is clear that further study is needed to assess the long-term outcomes of Artisan lenses in children to include data on rates of de-enclavation in different patient groups, according to technique and age at surgery.

\section{Conflict of interest}

The authors declare no conflict of interest.

\section{References}

1 Lifshitz T, Levy J, Klemperer I. Artisan aphakic intraocular lens in children with subluxated crystalline lenses. J Cataract Refract Surg 2004; 30(9): 1977-1981.

2 American Academy of Ophathlmology. Basic and Clinical Science Course. Section 11: Lens and Cataract. American Academy of Ophthalmology: San Francisco, CA, USA, 2015.

3 Wilson ME, Trivedi RH. Choice of intraocular lens for pediatric cataract surgery: survey of AAPOS members. J Cataract Refract Surg 2007; 33(9): 1666-1668.

4 Buckley EG. Scleral fixated (sutured) posterior chamber intraocular lens implantation in children. J AAPOS 1999; 3(5): 289-294.

5 Buckley EG. Hanging by a thread: the long-term efficacy and safety of transscleral sutured intraocular lenses in children (an American Ophthalmological Society thesis). Trans Am Ophthalmol Soc 2007; 105: 294-311.

6 Hoffman RS, Fine IH, Packer M, Rozenberg I. Scleral fixation using suture retrieval through a scleral tunnel. J Cataract Refract Surg 2006; 32(8): 1259-1263.

7 Bardorf CM, Epley KD, Lueder GT, Tychsen L. Pediatric transscleral sutured intraocular lenses: efficacy and safety in 43 eyes followed an average of 3 years. J AAPOS 2004; 8(4): 318-324.

8 Henning A, Evans JR, Pradhan DA, Pradhan D, Johnson GJ, Pokhrel RP et al. Randomised controlled trial of anteriorchamber intraocular lenses. Lancet 1997; 349(9059): 1129-1133.

9 Hindle NW CJ. Dislocation of the lens in Marfan's syndrome. Its effect and treatment. Can J Ophthalmol 1969; 4 (2): 128-135.

10 Miraldi Utz V, Coussa RG, Traboulsi EI. Surgical management of lens subluxation in Marfan syndrome. J AAPOS 2014; 18(2): 140-146. 
11 Worst JGF, Van der Veen G, Los LI. Refractive surgery for high myopia. The Worst-Fechner biconcave iris claw lens. Doc Ophthalmol 1990; 75(3-4): 335-341.

12 Gawdat GI, Taher SG, Salama MM, Ali AA. Evaluation of Artisan aphakic intraocular lens in cases of pediatric aphakia with insufficient capsular support. J AAPOS 2015; 19(3): 242-246.

13 Van Der Pol BAE, Worst JGF Iris-Claw. intraocular lenses in children. Doc Ophthalmol 1996; 92(1): 29-35.

14 Sminia ML, Odenthal MTP, Gortzak-Moorstein N, Wenniger-Prick LJJM, Völker-Dieben HJ. Implantation of the Artisan ${ }^{\circledR}$ iris reconstruction intraocular lens in 5 children with aphakia and partial aniridia caused by perforating ocular trauma. J AAPOS 2008; 12(3): 268-272.

15 Nucci P, Brancato R, Mets MB, Shevell SK. Normal endothelial cell density range in childhood. Arch Ophthalmol 1990; 108(2): 247-248.

16 Bahn CF, Glassman RM, MacCullum DK, Lillie JH, Meyer RF, Robinson BJ et al. Postnatal development of corneal endothelium. Investig Ophthalmol Vis Sci 1986; 27: 44-51.
17 Kora Y, Inatomi M, Fukado Y, Marumori M, Yaguchi S. Long-term study of children with implanted intraocular lenses. J Cataract Refract Surg 1992; 18(5): 485-488.

18 Basti S, Aasuri MK, Reddy S, Reddy S, Rao GN. Prospective evaluation of corneal endothelial cell loss after pediatric cataract surgery. J Cataract Refract Surg 1998; 24(11): 1469-1473.

19 Budo C, Hessloehl JC, Izak M, Luyten GP, Menezo JL, Sener BA et al. Multicenter study of the Artisan phakic intraocular lens. J Cataract Refract Surg 2000; 26(8): 1163-1171.

20 Anbari A, Lake DB. Posteriorly enclavated iris claw intraocular lens for aphakia: long-term corneal endothelial safety study. Eur I Ophthalmol 2014; 25(3): 208-213.

21 De Silva SR, Arun K, Anandan M, Glover N, Patel CK, Rosen P. Iris-claw intraocular lenses to correct aphakia in the absence of capsule support. J Cataract Refract Surg 2011 Sep; 37(9): 1667-1672.

22 Setala K, Ruusuvaara P, Karjalainen K. Corneal endothelium in Marfan syndrome. A clinical and specular microscopic study. Acta Ophthalmol (Copenh) 1988; 66(3): 334-340. 